Revue

Revue de l'histoire des religions

de Ihistoire des religions

$3 \mid 2012$

Varia

\title{
François DUINE, Souvenirs et observations, texte édité par Bernard HEUDRÉ avec la collaboration d'André DUFIEF
}

Rennes, Presses universitaires de Rennes (« Mémoire commune »), 2009, 348 p., 24 cm, $20 €$, ISBN 978-2-7535-0960-3.

\section{Alain Rauwel}

\section{OpenEdition}

\section{Journals}

Édition électronique

URL : http://journals.openedition.org/rhr/7955

DOI : 10.4000/rhr.7955

ISSN : $2105-2573$

Éditeur

Armand Colin

Édition imprimée

Date de publication : 1 septembre 2012

Pagination : 455-458

ISBN : 978-2200-92975-0

ISSN : 0035-1423

Référence électronique

Alain Rauwel, «François DuINE, Souvenirs et observations, texte édité par Bernard heudré avec la collaboration d'André DUFIEF », Revue de l'histoire des religions [En ligne], 3 | 2012, mis en ligne le 05 octobre 2012, consulté le 22 septembre 2020. URL : http://journals.openedition.org/rhr/7955 ; DOI : https://doi.org/10.4000/rhr.7955

Ce document a été généré automatiquement le 22 septembre 2020

Tous droits réservés 


\section{François DUINE, Souvenirs et} observations, texte édité par Bernard HEUDRÉ avec la collaboration d'André

\section{DUFIEF}

Rennes, Presses universitaires de Rennes (« Mémoire commune »), 2009, 348 p., 24 cm, $20 €$, ISBN 978-2-7535-0960-3.

\section{Alain Rauwel}

\section{RÉFÉRENCE}

François DUINE, Souvenirs et observations, texte édité par Bernard HEUDRÉ avec la collaboration d'André DUFIEF, Rennes, Presses universitaires de Rennes (" Mémoire commune »), 2009, 348 p., 24 cm, $20 €$, ISBN 978-2-7535-0960-3.

1 Dans sa grande thèse sur la crise moderniste, Émile Poulat n'avait rencontré l'abbé François Duine que parmi les correspondants de Houtin. Le manuscrit des Souvenirs et observations, déposé à la Bibliothèque nationale, n'avait pas encore été intégré à l'« état des sources existantes en Europe occidentale pour une histoire du modernisme» qu'Alphonse Dupront appelait de ses vœux. Malgré des fidélités persistantes, il a fallu que Pierre Riché signalât brièvement, dans les Mélanges Delumeau, l'extraordinaire intérêt des cahiers du prêtre rennais pour que s'engageât le processus éditorial qui nous donne accès aujourd'hui à ce document de premier ordre, qui est aussi un régal de lecture.

2 François Duine aimait à s'appeler clericus dolensis : son attachement à Dol, cette petite ville qui tenta au Moyen Âge de s'ériger en métropole, ne faiblit jamais, et il lui consacra quelques-unes de ses meilleures études. Car Duine est avant tout l'un des grands historiens de la Chrétienté bretonne, dont le Memento des sources hagiographiques 
pour l'histoire de Bretagne demeure, après 90 ans, sur la table des vrais érudits. Même si cette dimension de sa vie est évoquée, notamment par quelques croquis incisifs (Arthur de La Borderie en "métropolitain du for extérieur » ou une esquisse de sociographie des sociétés savantes rennaises), ce n'est pas elle qui domine dans les Souvenirs. Celui qui fut le biographe de Lamennais a voulu s'y peindre au naturel, et d'abord pour luimême, entretenant l'incertitude sur les destinataires éventuels de ses méditations. Cette absence totale de «style pieux » donne tout son prix au récit : pour une fois, on n'est pas obligé de lire entre les lignes ou de comprendre à demi-mot pour saisir l'état d'esprit d'un prêtre français entre Concordat et guerre mondiale. L'itinéraire est d'une banalité affligeante: milieu familial rude, séminaire comme unique ascenseur social pour un bon élève pauvre, formation marquée du double sceau du psittacisme et du caporalisme, ordination vécue comme une évidence, choc du réel. Il n'est éclairé que par l'exceptionnelle intelligence et la sensibilité délicate d'un lettré, dont la passion des classiques et la bonté souriante ne sont pas sans évoquer un chanoine Mugnier. Une personnalité si libre, si originale, ne devait pas manquer, dans l'Église de France telle qu'elle était sous la III République, de susciter l'incompréhension, le soupçon, la réprobation. Ce fut d'autant plus le cas que le jeune Duine, sans illusion sur la qualité morale du clergé paroissial, demanda à passer à l'Oratoire de France. Il n'y trouva pas les satisfactions qu'il espérait et dut solliciter sa réintégration dans son diocèse : on le lui fit payer.

3 C'est l'occasion pour l'observateur discret mais impitoyable de confier à son cahier un tableau au vitriol de tous les milieux du clergé séculier, à côté duquel les personnages de L'Anneau d'améthyste feraient presque figure de saints de vitrail. Comme il l'écrit luimême dans son avant-propos, "ces pages contiendront pour les historiens futurs de l'Église un tableau rare par l'exactitude et la franchise des traits». Les palais épiscopaux de l'âge concordataire sont visités sans complaisance, entre majesté dérisoire de prélats ignorants et servilité calculatrice de seconds couteaux occupés à faire carrière. De ce point de vue, la liquidation de l'Oratoire de Rennes par l'administration diocésaine, sur laquelle Duine fournit un témoignage de première main, hésite entre Le Lutrin et Eugène Sue. Le destin de l'abbé Trochu, puissant directeur de L'Ouest-éclair, est celui d'un «mercanti ensoutané». Mais le monde des presbytères de campagne ne vaut pas mieux : les Souvenirs ne sacrifient en rien au topos du bon curé, fond de commerce de toute une littérature dont l'auteur, en deux pages brillantes, trace le profil. Vicaire de bourgade avant d'être promu à Vitré, Duine aligne de ses confrères une galerie de portraits frisant parfois le tératologique. Les années de ministère paroissial sont pour lui une épreuve qu'il tente d'oublier en composant, en bon prêtre érudit, la monographie de son village de Guipel. Son intérêt pour les traditions populaires est un indice de la faveur du «folklore » dans le monde savant de 1900.

De 1908 à sa mort brutale en 1924 (alors qu'il n'était âgé que de 54 ans), François Duine est aumônier des lycées (de garçons et de filles) de Rennes. Les statistiques qu'il donne sur la pratique religieuse dans les établissements publics de cette époque seront précieuses aux historiens. Pour lui, il trouve enfin, dans une grande ville qui facilite son travail, dans une charge qui lui permet de fréquenter des universitaires, dans un genre de vie qui le soustrait à la promiscuité cléricale, un relatif équilibre - bientôt rompu, toutefois, par la Grande guerre. Esprit libre jusqu'au bout, l'abbé ne sacrifie pas au Moloch patriotique. Il voit dans l'idéologie dont se nourrit l'Europe ensanglantée « la synthèse de tous les mensonges et de toutes les férocités ». Sur ce plan là aussi, l'édition 
des Souvenirs apporte du neuf : à une histoire de la lucidité navrée face au désastre du Vieux continent, limitée jusqu'ici aux élites intellectuelles, elle offre la figure d'un solitaire de province, qui aspire sans trop d'illusions à «des générations moins hallucinées et moins saisissables aux puissances de mensonge ».

5 L'abbé Duine fut catalogué par ses supérieurs comme peu sûr, potentiellement moderniste. Le diagnostic était-il juste? Des éléments indubitables vont dans ce sens. Duine est aussi éloigné que possible du mépris du monde ou de la peur apocalyptique (au sens un peu attrape-tout que Paul Airiau a donné à ce terme), si fréquents dans les milieux catholiques d'alors. Bien que dépourvu de toute naïveté, il aime son temps et ne rêve pas au rétablissement de Chrétientés défuntes. Aumônier, il déclare se donner pour tâche d'" aimer [s]on siècle pour lui faire aimer l'Église». On ne sera donc pas étonné qu'il éprouve une vive sympathie pour le Sillon. À l'inverse, le système romain, qu'il désigne comme "pidisme ", lui est aussi étranger qu'antipathique. Il dénonce ce qui lui apparaît comme « la Terreur de sacristie ». Dans cette attitude, il semble qu'il ne soit pas isolé, comme tendrait à le prouver cette réaction d'un confrère lorsqu'est imposé le serment anti-moderniste : « ça a autant d'importance que si l'on jurait que la lune est en peau de castor »! Mais il partage l'hostilité générale des catholiques face aux violences de la Séparation; à ses yeux pourtant, provocations et coups d'éclat se nourrissent d'un camp à l'autre, dans le cadre de "l'état de chose combisto-pidiste ».

6 Allons plus loin : quelle était la foi de l'abbé Duine? Avait-elle succombé sous le flot répété des déceptions? C'est ce qu'affirmerait qui ne mesurerait la foi qu'à l'aune de l'adhésion aux axiomes scolastiques. De ceux-là, certes, Duine a pris congé, et avec une ironie à l'occasion franchement voltairienne. Au séminaire, il constate: «ne faisons plus jamais d'objections : amen est le mot de ce pays-ci ». Mais le voltairianisme n'est pas son dernier mot. S'il impose au dogme le bénéfice de l'inventaire, il garde sans hésiter la morale. Tout ce qui élève, dématérialise, affine, lui parait bon, et la force de l'Évangile, du christianisme, de l'Église même, est de permettre et de promouvoir une telle élévation. Point de vue courant parmi les combattants de la crise moderniste, et qui fut un temps celui de Loisy. Point de vue très renanien, aussi. La parenté entre le clerc de Dol et son aîné de Tréguier est ici évidente. Le sacerdoce, plus que le culte d'une divinité singulière, est pour eux celui de l'idéal, du Bon et du Beau. Et lorsque le jeune lévite s'enflamme de pouvoir "unir dans [s]a vie le Parthénon et la Cathédrale », on entend comme un écho de la Prière sur l'Acropole. Il n'est pas jusqu'à la passion des vieux saints celtiques qui ne réunisse les deux hommes - même si l'on demeure surpris de l'assimilation de Tyrell, "l'une des figures les plus attachantes de l'histoire religieuse de tous les temps", au "saint celtique du modernisme». Seuls les choix institutionnels séparent Duine du modèle renanien. Et encore ! Un certain Renan aurait pu souscrire à ces ultima verba : «j'aime l'Église de toute mon âme. Pourtant, j'aimerais bien qu'on pût penser à l'aise sans être suspect. J'ai confiance dans le triomphe final du catholicisme évangélique ».

7 Si la rencontre avec Duine est saisissante, comme peut l'être ailleurs celle d'un autre exilé du modernisme, l'abbé Grosjean, les Souvenirs éclairent aussi d'autres itinéraires que le sien propre, à commencer par celui d'un Rennais bien plus connu, Joseph Turmel. L'ouvrage, qui compte 40 pages sur «Herzog-Dupin» et ses entours, constituera désormais l'une des pièces majeures à verser au dossier Turmel. François Duine, tout effrayé qu'il soit par la "puissance de haine infatigable » du prêtre athée, ne peut en effet se départir d'un intérêt persistant pour l'homme et l'œuvre (dont il n'a 
pas vu la catastrophe, advenue six ans après sa mort) : raison de plus pour lire avec attention les cahiers qu'il a laissés, dont l'édition devra être rangée parmi les usuels par tous ceux qui s'intéressent à cette crise majeure du monde catholique que fut le moment moderniste.

\section{AUTEURS}

ALAIN RAUWEL

Université de Bourgogne, Dijon. 